\title{
Research on the Development of Core Literacy of Middle School and Primary School Students
}

\author{
Zhang Xiaoting ${ }^{1}$, Zhang Xiaona ${ }^{2}$ \\ ${ }^{1}$ Harbin Experimental School, 150028, China \\ ${ }^{2}$ Harbin Experimental School, 150028, China
}

Keywords: Primary and middle school students; key competency; Cultivating path

\begin{abstract}
Key competency is a matter closely followed by international education reform, and the primary and middle school stage is an important stage of cultivating students' key competency. Therefore, we must strengthen the research on the development of key competency of middle school and primary school students. This paper first discusses the related concepts of key competency. Secondly, it analyzes the problems that arise in the process of cultivating the key competency of primary and middle school students. Finally, aiming at these problems, this paper explores the main path of cultivating the key competency of primary and middle school students, namely, optimizing the teachers' skills based on the core accomplishment, carrying out the curriculum reform based on the core accomplishment, and improving the student evaluation mechanism based on the key competency.
\end{abstract}

\section{中小学教育中学生核心素养发展研究}

\author{
张晓婷 ${ }^{1}$, 张晓娜 ${ }^{2}$ \\ 1.哈尔滨市实验学校, 哈尔滨 150028 \\ 2.哈尔滨市实验学校, 哈尔滨 150028
}

关键词: 中小学生; 核心素养; 培养路径

摘 要: 核心素养是国际教育改革密切关注的问题，而中小学阶段是培养学生核心素养的重 要阶段。因此我们必须要强化对中小学教育中学生核心素养的发展研究, 本文首先论述了核 心素养的相关概念; 其次分析了当前培养中小学生核心素养过程中出现的问题; 最后针对这 些问题，探究培养中小学生核心素养的主要路径，即优化基于核心素养的教师技能、开展基 于核心素养的课程改革、完善基于核心素养的学生评价机制。

\section{1. 引 $\square$ 言}

近年来，随着全球化、信息化时代与知识社会的来临，打破了传统的经济模式和职业模式， 进而对未来社会人才的培养提出了更高的要求。例如, 要具有独立思考能力, 创造思维, 掌 握人类文明进程和全球发展动态; 勇于尝试人类面临的全球性挑战; 要有信息意识, 可以有 效地使用信息，把握信息技术；此外还要具备自我把控的能力，人与人之间的合作能力。总 之, 新时代需要培养人才的关键素质和综合能力。由此, 基于全民终身学习视角的核心素养 应运而生，并在国际上开启了新一轮教育与课程的改革。

\section{2. 核心素养的内涵}

所谓核心素养，是指“学生在接受相应学段教育过程中，逐步形成适应个人未来终身发展和 社会发展需要的必备品格和关键能力。”核心素养已经成为当今国际组织与政府进行教育改 革的热点问题。关于核心素养的构成要素，世界各国、各组织的说法不一，比如，经济合作 与发展组织的“素养的界定与遴选”项目指出，要保证人的成功与健全社会的建设，个体必须 
具备三大核心素养: 能在社会异质团体中互动、能互动地使用工具、能自主行动; 欧盟从终 身学习角度, 提出了八大核心素养: 母语交流、外语交流、数学素养、科学技术素养、信息 素养、主动与创新意识、学会学习、社交与公民素养、文化意识与表达; 美国“21 世纪核心 素养” 融入 21 世纪学习体系, 主要包含学习和创新素养, 信息、媒体与技术素养, 生活与职 业素养三个方面; 新加坡教育部在已有的《理想教育的目标》基础上, 提出了 21 世纪学生核 心素养新框架, 以“核心价值观”为核心培养学生的自我决策、自我意识、自我管理能力、人 际素养、社会性意识六大核心素养。

2016 年 9 月我国发布了《中国学生发展核心素养》(征求意见稿)。以培养“全面发展的人” 为核心, 分为文化基础、自主发展、社会参与三个方面。综合表现为人文底蕴、科学精神、 学会学习、健康生活、责任担当、实践创新六大素养, 其中每个核心素养包括三个基本要点, 细化为社会责任等十八个基本要点。我国学生发展核心素养是以时代性、科学性和民族性为 基本原则, 以学生全面发展为主题, 以课程改革为切入点, 从多方面构建系统化的育人体系。

尽管各国际组织与各国政府提出的核心素养内涵在内容上存在着差异, 但都有互相融合与 互补之处, 可以看出核心素养是个多功能、多维度的概念, 是知识、技能、态度的综合体。 核心素养的提出迎合了时代发展所需, 它可以统领一个国家教育改革的方向。因此, 培养学 生核心素养将成为我国教育发展的主导方向。

\section{3. 中小学教育中学生核心素养发展存在的问题}

核心素养的出现，引发了教育界空前的追捧，但在落实上还存在着一些问题。

第一, 教师重教书轻育人。传统教育的特点是注重知识的传承, 把理解知识作为教学的重 点。这种偏重于知识的教学是长期的历史积淀的结果, “知识就是力量” 思想扎根人们心中已 久, 把知识视为绝对真理, 从而忽略了对学生创新意识、实践能力、批判质疑的等素养的培 养。受传统教育的影响, 以及迫于学校给教师的成绩压力等多重因素, 导致现在的教师对核 心素养进课堂的重视程度不够。另外, 基于核心素养的课堂教学是一种开放式的教学, 课堂 中往往会出现一些没有预设到的不可控事件, 给传统的教师角色带来挑战, 教师不再只是知 识的传播者, 还会变成学生的合作者。同时, 综合性的课堂教学, 也给教师带来更多的知识 和信息上的挑战, 教师需要花费更多的精力和时间去查找相关资料, 否则无法顺利地与学生 合作, 无法对学生的学习行为进行有效的评价。这些不可控因素都会给教师带来不安与焦虑, 进而影响了核心素养进课堂的进程。

第二, 课程改革落实不到位。课程是教育改革的“良方”, 它是培养学生核心素养的重要教 育资源。但有些学校对培养学生核心素养的校本课程开发力度不够, 课程结构单一, 甚至出 现 “千校一面” 的现象。另外, 由于核心素养概念界定模糊, 具体维度表述不够清晰, 导致学 科的霸权地位很难从根本上被撼动, 素养教学就成了学科教学的点缀。

第三, 核心素养测量与评价体系不够完善。我国现有教育教学质量评价, 过度重视学生的 学习成绩, 而忽视了学习过程的评价, 这样的评价方式不能满足培养学生核心素养的需要。 为此，需要完善现有的教育质量评价制度，以便更好评估核心素养起到的教育意义。

\section{4. 中小学生核心素养培养路径}

\section{1 优化基于核心素养的教师技能}

培养学生的核心素养, 需要教师将注意力从知识点的传授转移到学生能力的培养, 从“教师 教什么, 怎么教”转移到“学生学什么, 怎么学”等问题上来。处理好“教书”和“育人”的关系。

如何改变教师“重知识, 轻能力”的传统教学观念, 增强教师对教育变革的积极性是当前教 育改革所面临的主要问题。

首先, 教师要有过硬的专业技能和精湛的教学技艺。教师只有具备了丰富的专业知识, 并 对学科知识有了深刻的理解, 才能更好地把握课标、教材、课改精神的方向, 才能让自己的 
课堂成为高效的课堂, 育人的课堂。

其次, 教师要多学习, 多思考。“核心素养”这一教育理念的出现, 在教育界掀起了热潮, 但很多教师对这一新鲜词汇却了解的微乎其微。所以学校要为教师多提供一些针对核心素养 教学的职业培训, 比如如何帮助学生学会学习, 培养学生理性思维, 鼓励他们健康生活, 创 造有利于学生探究、质疑和反思的学习环境等。同时教师自身更要不断地学习和思考如何通 过自己的课去培养学生的综合能力。

最后, 教师要转变思想, 开展课程教学研究。长期以来, 一线教师只是在教学生理论知识 和答题技巧, 注重研究所教教材和学科知识, 很少宏观和系统地研究课程的教育目的和意义。 只有从思维的高度把握教育的方向，才会对我国的教育工作有着长远的发展意义。教师可以 以学科专家的身份参与到学校课程的编制、实施、管理与评价的整个过程中来。这能带给教 师更多的职业威严, 增强教师在课程改革中的归属感和成就感, 还能帮助教师以更开阔的视 野去看待教育。教学案例一, 在教学一线有这样的真实案例, 同样执教人教版语文三年级上 册《风筝》, 两位教师设计了一模一样的问题, 教育起点完全相同, 但教育的落脚点却大相径 庭, 如表 1 所示。

\section{表 1 《风筝》的教学片断}

Table 1 Teaching fragment of "Kite"

\begin{tabular}{|c|c|c|c|}
\hline \multirow{3}{*}{$\begin{array}{c}\text { 教学设 } \\
\text { 计 }\end{array}$} & \multicolumn{3}{|c|}{ 课堂生成 } \\
\hline & \multirow{2}{*}{ 学生表现 } & \multicolumn{2}{|r|}{ 教师表现 } \\
\hline & & 甲教师 & 乙教师 \\
\hline \multirow{3}{*}{$\begin{array}{c}\text { 学生默 } \\
\text { 读课后 } \\
\text { “资料 } \\
\text { 袋”回 } \\
\text { 答: “关 } \\
\text { 于风筝, } \\
\text { 你有哪 } \\
\text { 些了 } \\
\text { 解?” }\end{array}$} & $\begin{array}{c}\text { 生 1: “风筝有两千多 } \\
\text { 年的历史。” }\end{array}$ & “说得好! ” & $\begin{array}{c}\text { “你抓住关键词“两千年”快 } \\
\text { 速捕捉到风筝的历史。很 } \\
\text { 好!” }\end{array}$ \\
\hline & 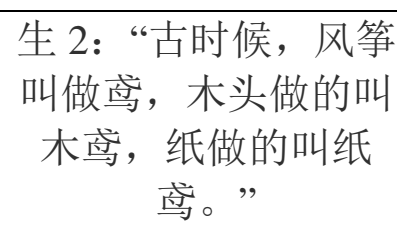 & “非常好！” & $\begin{array}{c}\text { “你关注“走”这个词, 知道了 } \\
\text { 风筝的来历。非常好! ” }\end{array}$ \\
\hline & $\begin{array}{c}\text { 生 3: “山东潍坊是风 } \\
\text { 筝之都。” }\end{array}$ & “很不错！” & $\begin{array}{c}\text { “你还捕捉到了风笔之乡的 } \\
\text { 信息。很不错! 如果能抓住 } \\
\text { 那些关键词, 把有关风筝的 } \\
\text { 信息连起来说一说, 就更棒 } \\
\text { 了。谁来试一试? ” }\end{array}$ \\
\hline
\end{tabular}

甲教师是典型的教教材, 以了解有关风笔的常识为目标, 是指向知识积累的教学。乙教师 是用教材教语文, 以培养学生抓住关键词捕捉信息的能力为目标, 关注方法支撑下的目标达 成, 鼓励学生“抓住关键词连起来说一说”这一举措具有发展性, 是指向核心素养的养成教育, 很语文!

\section{2 开展基于核心素养的课程改革}

课程是核心素养的重要载体。目前我国的现行的课程体系主要以传授知识为主, 这种学科 导向下的知识结构体系完整、科学, 能为学生打下良好的知识基础, 但并不利于培养学生的 素养和能力。随着课程改革的不断深入, 必然会越来越注重学生综合素养的提高。课程结构 的调整和优化便成了大势所趋。为此, 必须要落实以下几点: (1)增加体验类、实践类等选修 课程, 丰富课堂内容, 设置情境教学, 为不同基础、不同发展方向的学生提供更多的选择机 会, 满足学生个性化需求。(2)多学科整合教学。选定一个主题, 与主题相关的各个学科教师 集体研修, 围绕主题剖析出可以培养的核心素养, 然后根据核心素养设计课程、上课的方式 和方法, 达到互补的目的。(3)跨学科整合教学。将有内在联系的不同学科内容整合在一起, 
设置“跨学科主题”课程, 对各学科的课程标准进行重组, 让学生多角度、多维度去理解概念, 从而实现真正地掌握知识。如哈尔滨市实验学校的机器人课程, 让学生亲手制作机器人, 可 以让孩子们掌握几何、机械、科学、工程、技术、多媒体、艺术等多种跨学科知识, 将这些 知识融汇于一个充满乐趣、挑战和团队合作的动手过程中。激发孩子们参与科技的兴趣, 启 发孩子们潜在的创造力, 让他们不断探索多种抽象理念在实际中的可能性, 鼓励他们用不同 的方法解决问题, 提高他们在合作中的交流, 沟通和分享技能, 教导孩子们体验和超越障碍, 建立自信和自尊。

\section{3 完善基于核心素养的学生评价机制}

学生的核心素养不是教师教出来的, 而是需要教师改变教学方式, 创设教学情境, 引导、 激励学生主动在实践和探究中逐步提升。课堂是丰富而且不可预估的, 仅凭个人的观察来了 解核心素养的落实情况是教师们力所不及的。这就需要在学生核心素养体系的指导下, 建立 科学、系统的评价体系。为了切实帮助教师通过课程了解如何开展好核心素养的教学, 落实 效果怎么样, 学生的课堂反应如何等问题, 哈尔滨市实验学校采用了课堂观察法。要求各学 科依据核心素养内容, 进行课堂观察量表的制作, 用于课堂观察。例如, 小学数学教研组根 据数学学科素养制定了以下的课堂观察量表, 如表 2 所示。

\section{表 2 小学数学学科素养课堂观察量表 (学生)}

Table 2 Primary school mathematics subject literacy classroom observation scale (student)

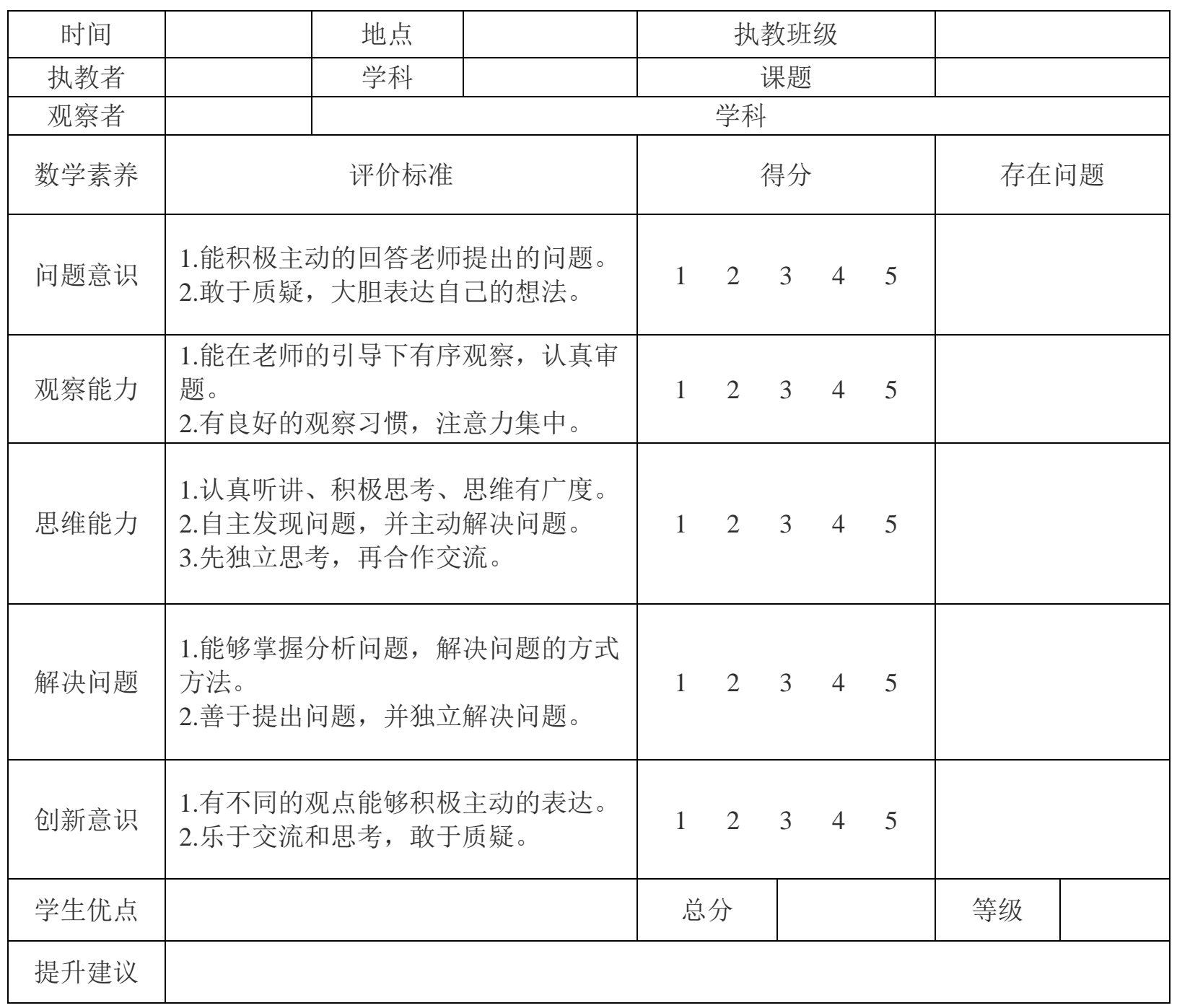

通过制定这样的课堂观察量表, 可以帮助教师更好地观察、思考自己或其他教师在教学过 程中存在的不足, 交流讨论出更多有利于学生自主实践和探究的教学方法, 为培养学生的核 
心素养打下坚实的基础。中小学教育作为基础性教育, 在培养学生的学习能力和综合素养方 面发挥着重要作用。只有科学地开展核心素养教育, 才能有效地促进学生核心素养的提高。

\section{[参 考 文 献]}

[1] 古丽扎伯克力.核心素养视角下中小学生积极心理的培养 [J]. 新疆社科论坛，2017， (5) :96-98.

[2] 左璜.基础教育课程改革的国际趋势:走向核心素养为本 [J]. 课程教材教法, 2016,36 (2) :39-46.

[3] 黄宝权.中小学生核心素养培养路径探析[J].教育探索, 2016,（11）:14-16.

[4] 王媛. 紫冰花开[M].上海:华东师范大学出版,2017:86-87.

[5]姜言霞, 卢巍. 中小学生发展核心素养现状调查研究[J]. 山东师范大学学报, 2017,62 (6) :94-104.

[6] 辛涛,姜宇.我国义务教育阶段学生核心素养模型的构建 [J]. 北京师范大学学报, 2013,(1):5-11.

[7] 张紫屏.基于核心素养的教学变革--源自英国的经验与启示 [J]. 全球教育展望, 2016, (7) :3-13.

[8] 高明旻.小学教育中学生核心素养发展研究[J].教学研究, 2018,(19):36-37.

[9] 钱柳娟.探究如何培养小学生的教学核心素养[J].都市家教(下半月), 2016,2（4）:102-103.

[10] 陈明武.在初中物理教学中如何培养学生核心素养[J].速读, 2016,（7）:24-25. 